九州大学学術情報リポジトリ

Kyushu University Institutional Repository

\title{
Nondestructive Internal Quality Inspection of Tomato Fruits
}

Hu, Wenzhong

Uchino, Toshitaka

Hamanaka, Daisuke

Laboratory of Postharvest Science, Division of Bioproduction System Science, Department of Bioproduction Environmental cience, Graduate School of Bioresource and Bioenvironmental

Sciences, Kyushu University

Sorour, Hussain

Postdoctoral Fellow of Japan Society for the Promotion of Science, Laboratory of Postharvest Science, Division of Bioproduction System Science, Department of Bioproduction Environmental cience, Graduate School of Bioresource and Bioenvironmental Sciences, Kyushu University

他

https://doi.org/10.5109/4512

出版情報：九州大学大学院農学研究院紀要. 47 (2)，pp.419-426，2003-02-01. Faculty of Agriculture, Kyushu University

バージョン：

権利関係 : 


\title{
Nondestructive Internal Quality Inspection of Tomato Fruits
}

\author{
Wenzhong HU', Toshitaka UCHINO, Daisuke HAMANAKA*, \\ Hussain SOROUR**, Yoshiaki HORI \\ and Shun-ichiro TANAKA
}

\author{
Laboratory of Postharvest Science, Division of Bioproduction System Science, Department of \\ Bioproduction Environmental Science, Faculty of Agriculture, \\ Kyushu University, Fukuoka 812-8581, Japan \\ (Received October 31, 2002 and accepted November 7, 2002)
}

\begin{abstract}
The synthetical analysis was carried out from specific gravity, firmness and Hunter color index by neural network to develop the new nondestructive method for evaluating soluble solid content, sugar and organic acid contents. The multiple regression analysis was also carried out to determine the possibility of predicting soluble solid content, sugar and organic acid contents. The results showed that there was no significant difference between experimental and calculated values of soluble solid content, indicating that soluble solid content could be predicted from specific gravity, firmness (calculated from $a^{*}$ value), $L^{*}, a^{*}$ and $b^{*}$ values by using neural network. It was also shown that the organic acid content could be estimated from specific gravity, firmness, hue, $\mathrm{L}^{*}, \mathrm{a}^{*}$ and $\mathrm{b}^{*}$ values. But there was significant difference between experimental and calculated values of sugar, demonstrating that it was impossible to predict the sugar content from specific gravity, firmness, hue, $\mathrm{L}^{*}, \mathrm{a}^{*}$ and $\mathrm{b}^{*}$ values by neural network. For the multiple regression analysis, although soluble solid content of tomato fruits was synthetically affected by many factors, it was greatly influenced by firmness and $a^{*}$ value of tomato fruits. For sugar and organic acid contents, both of them were markedly affected by firmness and specific gravity.
\end{abstract}

\section{INTRODUCTION}

Nondestructive method is widely used in evaluating quality of fruits to determine the optimum harvest date, taking into account the targeted fruit market maintenance of fruit quality during storage and market. It is essential to provide good quality of tomato fruit for consumers. Measurement of soluble solids content with a refractometer is quick and easy but is destructive and requires a large sample size to be reliable. The extensive research is currently being conducted on developing non-destructive methods to provide information on fruit ripeness and quality. Recent publications have been focused on the development of non-destructive techniques for measuring quality attributes of tomatoes such as sugar content and firmness (Iwao et al., 1989; Kawano et al., 1993; Choi et al., 1995; Olmo et al., 2000; Sugiura et al., 2001). In a previous paper, the results of pre-

* Laboratory of Postharvest Science, Division of Bioproduction System Science, Department of Bioproduction Environmental Science, Graduate School of Bioresource and Bioenvironmental Sciences, Kyushu University

** Postdoctoral Fellow of Japan Society for the Promotion of Science, Laboratory of Postharvest Science, Division of Bioproduction System Science, Department of Bioproduction Environmental Science, Kyushu University

† Corresponding author (E-mail:huxu@agr.kyushu-u.ac.jp) 
dicting soluble solid content of tomato fruits by specific gravity and surface color were reported (Hu et al., 2002). Further, relations between specific gravity and organic acid content have also been discussed by using regression analysis as well as relation between malic acid content and surface color. However, the quality attributes of tomato are not mainly affected by one factor such as surface color or firmness, while they should be evaluated by using the combination of many factors. In this study, our objectives were to better understand the interaction among the factors such as specific gravity, firmness, $\mathrm{L}^{*}$, $\mathrm{b}^{*}$ and $\mathrm{a}^{*}$ values, sugar and organic acid contents by using the neural network. The multiple regression analysis was carried out to determine the possibility of predicting sugar, organic acid and soluble solid contents based on surface color, specific gravity and firmness of tomato fruit.

\section{MATERIALS AND METHODS}

\section{Plant materials and measurements}

The tomato fruits (Lycopersicon esculentum Mill) with different maturity (variety: Momodaro) were harvested from a local greenhouse in Fukuoka Prefecture, Japan and transported from the cultivation area to laboratory within $1 \mathrm{~h}$ for experiment. Specific gravity was determined from the volume and weight of tomato fruits. The firmness of each tomato fruit was assessed by sclerometer (model FHK, Fuji Hira Industy, LTD, Tokyo, Japan) equipped with an 8-mm diameter plunger. The measurement was carried out at 5 different points (one each at the blossom and stem ends and three in equatorial position) on each tomato fruit with a chromameter (model CR 200; Minolta Corp., Japan). Dial readings were measured in $\mathrm{kg}$. Expression of tomato color was characterized as Hunter color indexes $\mathrm{L}^{*}, \mathrm{a}^{*}$ and $\mathrm{b}^{*}$. The soluble solid content in the extracted juice was measured using a refractometer (Atago IATC-1E, Osaka, Japan) and expressed in percentage. Sugar (total of glucose, fructose and sucrose) contents in tomato fruits were determined by HPLC equipped with NH2P-50 column $(4.6 \mathrm{~mm} \phi \times 250 \mathrm{~mm})$ at $40^{\circ} \mathrm{C}$. The mobile phase was acetonitrile : water $=75: 25$ at a flow rate of $1.0 \mathrm{ml} \mathrm{min}^{-1}$ and injection volume was $20 \mu \mathrm{l}$. Organic acid content was also determined using HPLC equipped with Shim-pack SCR-102H column $(8 \mathrm{~mm} \phi \times 30 \mathrm{~cm})$ (Shimadzu model, Shimadzu Corp., Tokyo Japan) packed with $\mathrm{H}$ type cation exchanger that consists of semi-rigid styrene-divinylbenzene copolymer under $40^{\circ} \mathrm{C}$. The mobile phase is $0.5 \mathrm{mM}$ $p$-toluenesulfonic acid and flow rate is $1.0 \mathrm{ml} \mathrm{min}^{-1}$.

Data were subjected to regression analysis of variance (ANOVA) at $95 \%$ significant level.

\section{Model development for neural network}

The neural network model was considered to be fully connected, multiplayer and error-backpropagation network. Structure of hybrid two-layer model was showed in Fig. 1. Hybrid network refers to a combination of different transfer functions in a single model. The model was trained by using the software with the automatic option of normalizing inputs and targets. In this study, 1589 training patterns and 300 testing patterns were used. The weights in the network were adjusted for every epoch of 1589 patterns. The number of iterations was set at 300000 while monitoring root mean square (RMS) 


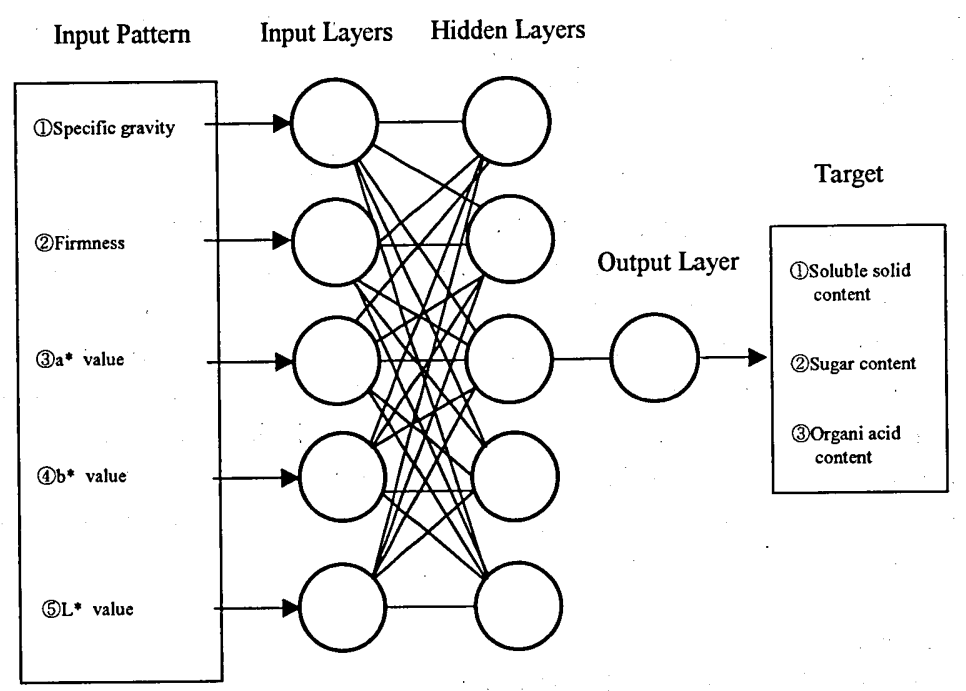

Fig. 1. Schematic diagram of 5-5-1 neural network architecture.

that indicates the output precision. The momentum of training $\alpha$ was set at 0.8 and learning rate $\eta$ at 0.001 . When the RMS was global minimum training was halted to avoid over training, and then the model was saved as trained model ready for testing different set of data for the authenticity of model.

\section{Data collection}

The data must have independent and dependent variables, and the data were used for training the model and attention must be given to the accuracy of the data. In this experiment, five inputs and one output were used for the predicting model (Fig. 1). The inputs were specific gravity, firmness, $\mathrm{L}^{*}, \mathrm{a}^{*}$ and $\mathrm{b}^{*}$ values. Outputs were sugar and organic acid and soluble solid contents, respectively.

\section{Multiple regression analysis}

Three modeling approaches were taken to describe the sugar, organic acid and soluble solid contents by using specific gravity, firmness, Hunter color parameters $\left(L^{*}, a^{*}\right.$, and $\left.b^{*}\right)$ and hue $\left(\sqrt{a^{2}+b^{2}}\right)$. The models were expressed as follows:

$$
\begin{aligned}
& C_{B}=a_{0}+a_{1} x_{S P}+a_{2} x_{F}+a_{3} x_{L}+a_{4} x_{a} \\
& C_{S}=a_{0}+a_{1} x_{S P}+a_{2} x_{F}+a_{3} x_{L}+a_{4} x_{a}+a_{5} x_{b} \\
& C_{0}=a_{0}+a_{1} x_{S P}+a_{2} x_{F}+a_{3} x_{L}+a_{4} x_{a}+a_{5} x_{b}+a_{6} x_{C}
\end{aligned}
$$

where $C_{B}$ is soluble solid content, $C_{S}$ is sugar content, $C_{o}$ is organic acid content, $x_{S P}$ is 
specific gravity, $x_{F}$ is firmness, $x_{L}$ is $L^{*}$ value, $x_{a}$ is $a^{*}$ value, $x_{b}$ is $b^{*}$ value, $x_{C}$ is $a_{1} \sim a_{6}$ hue, is partial regression coefficient, $a_{0}$ is constant.

\section{RESULTS AND DISCUSSION}

In a previous report, it was shown that the soluble solid content of tomato fruits was strongly correlated to specific gravity, indicating that the soluble solid content of tomato fruits could be determined by specific gravity nondestructively (Hu et al., 2002). But there was a significant effect of some factors such as cavity and organic acid. It has been reported that the quality of tomatoes can be assessed by their visual appearance, firmness and ratio of total soluble solids to acidity (Hobson et al., 1983; Yang and Chinnan, 1987). Kawano (1998) has confirmed that these are major factors in the consumer acceptance of tomatoes. In this study, synthetical analysis was carried out for specific gravity, firmness and Hunter color by using neural network.

\section{Soluble solid content}

Fig. 2 shows that experimental and calculated values for soluble solid content of tomato fruits estimated from specific gravity, firmness and Hunter color index by neural network. There were only 2 samples over $1 \%$ difference between experimental and calculated values. There was also no significant difference by $\mathrm{T}$-test of significance at $5 \%$ level. It demonstrated that soluble solid content could be predicted from specific gravity, firmness, $\mathrm{L}^{*}, a^{*}$ and $\mathrm{b}^{*}$ values by using neural network. But for the firmness in analysis,

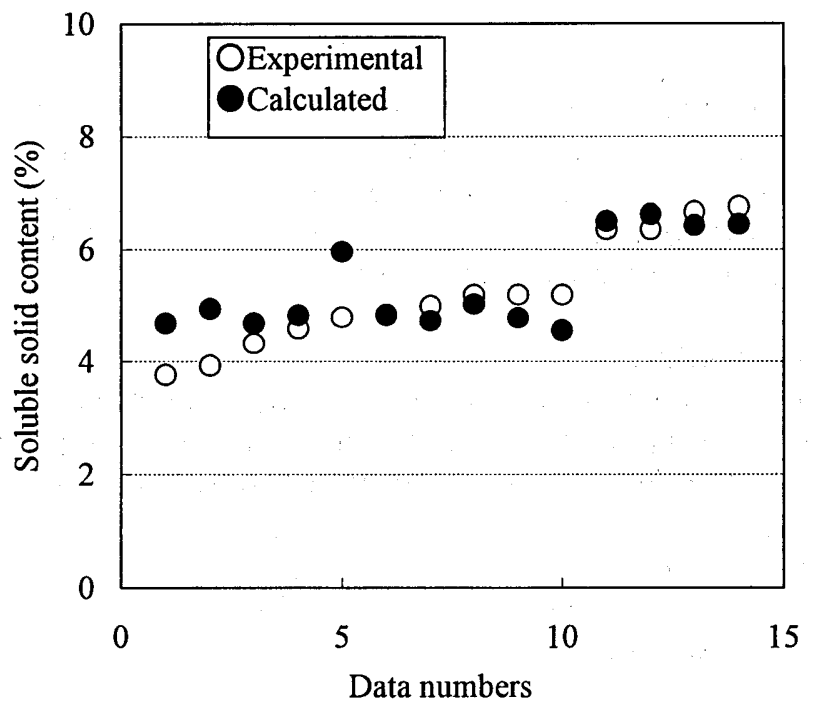

Fig. 2. Experimental and calculated values for soluble solid content of tomato fruit estimated from specific gravity, firmness and Hunter color index by neural network. 
the value was measured destructively. Therefore, value of firmness was calculated based on the relationship between firmness and $a^{*}$ value (data not shown). Fig. 3 shows that experimental and calculated values for soluble solid content of tomato fruits estimated from specific gravity, calculated value of firmness and Hunter color index by neural network. There was only 1 sample over $1 \%$ difference between experimental and calculated values. There was no significant difference by $\mathrm{T}$-test of significance at $5 \%$ level. It was considered that soluble solid content in tomato fruits could be predicted accurately by nondestructive method.

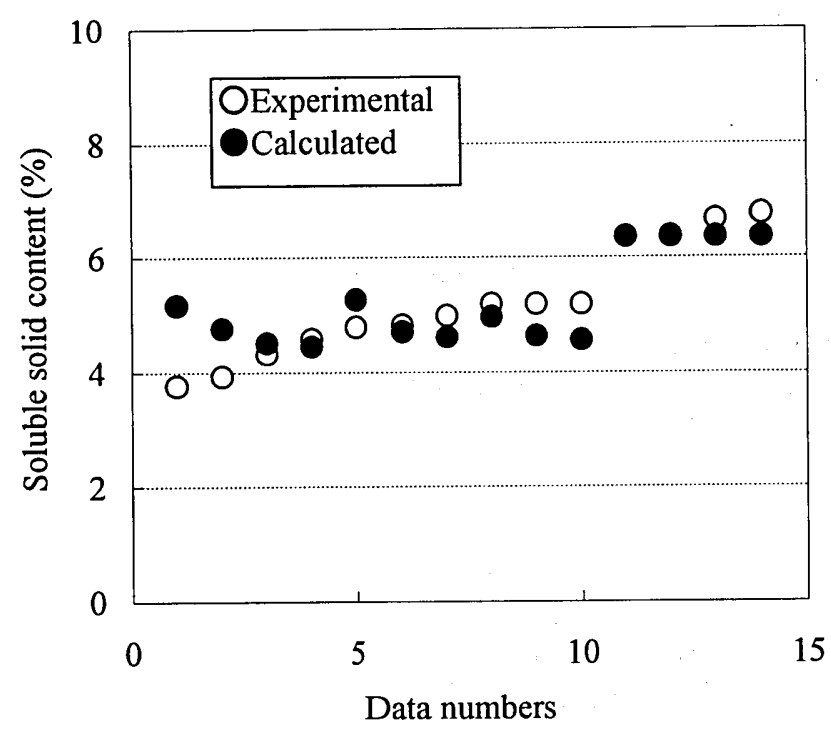

Fig. 3. Experimental and calculated values for soluble solid content of tomato fruit estimated from specific gravity, calculated value of firmness and Hunter color index by neural network.

\section{Sugar content}

Fig. 4 shows that experimental and calculated values for sugar content of tomato fruits estimated from specific gravity, firmness, hue and Hunter color index by neural network. There were 10 samples over $10 \mathrm{mg} \mathrm{ml}^{-1}$ difference between experimental and calculated values of sugar content. It was also shown that there was a significant difference by test of significance at $5 \%$ level, indicating that it was impossible to predict the sugar content from artificial neural network by using specific gravity, firmness, hue, $\mathrm{L}^{*}, \mathrm{a}^{*}$ and $\mathrm{b}^{*}$ values.

\section{Organic acid content}

Fig. 5 shows experimental and calculated values for organic acid content of tomato fruits estimated from specific gravity, firmness, hue and Hunter color index by neural 


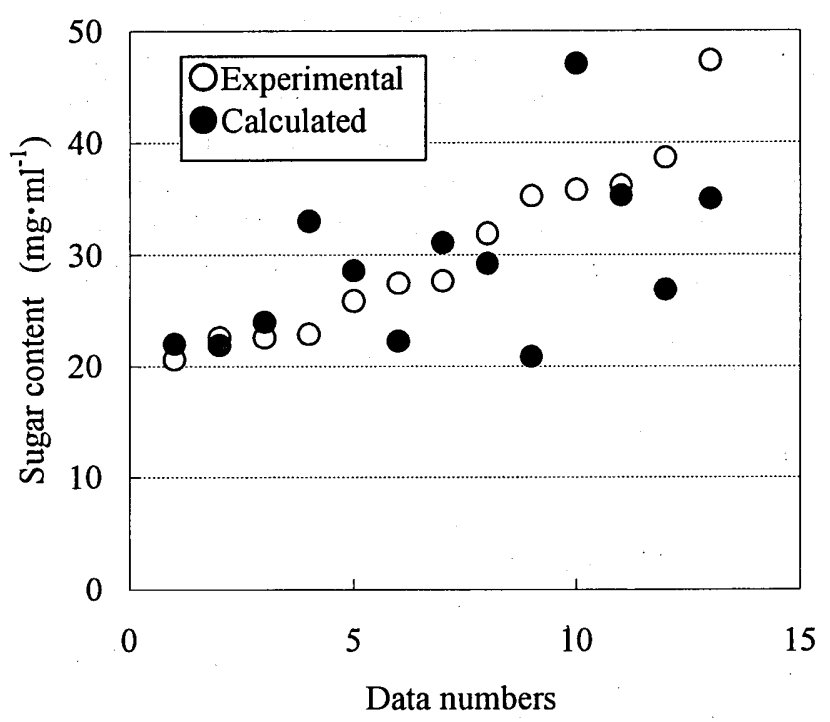

Fig. 4. Experimental and calculated values for sugar content of tomato fruit estimated from specific gravity, firmness, hue and Hunter color index by neural network.

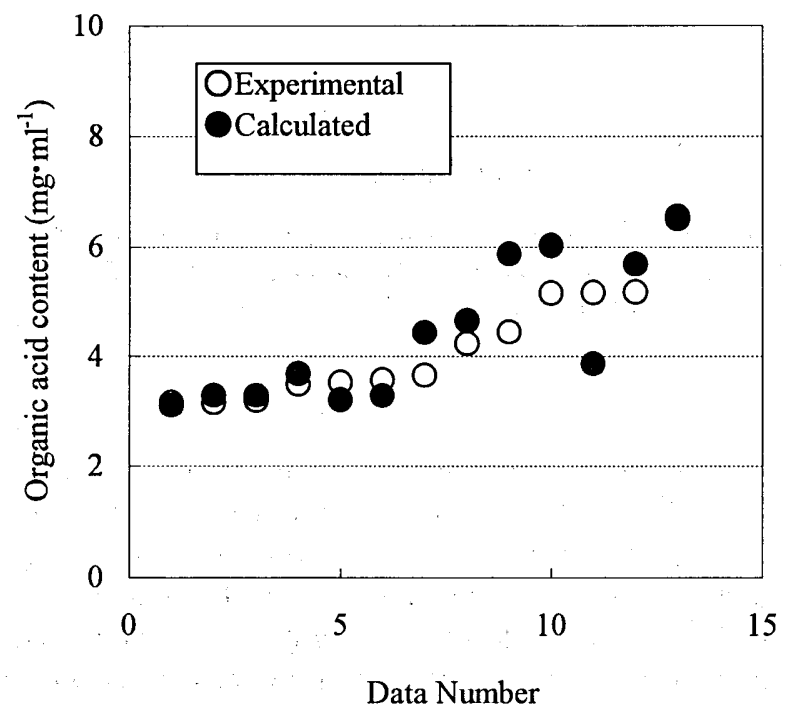

Fig. 5. Experimental and calculated values for organic acid content of tomato fruit estimated from specific gravity, firmness, hue and Hunter color index by neural network. 
network. Although there was great difference of 3 samples, experimental and calculated values showed similar changing trend with data numbers. For test of significance, it was shown that there was no significant difference at $5 \%$ level, indicating that it was possible to estimate the organic acid content from specific gravity, firmness, hue, $L^{*}, a^{*}$ and $b^{*}$ values by using neural network.

\section{Multiple regression analysis}

Table 1-3 shows the results of multiple regression analysis for sugar, organic acid and soluble solid contents. The degree of effect of some factors can be determined by standard regression coefficient of each factor. In Table 1 , among the four factors of $a^{*}$ and $\mathrm{L}^{*}$ values, firmness, specific gravity, standard regression coefficient of firmness and $a^{*}$ value were the largest $(0.817$ and 0.453 , respectively), indicating that the soluble solid content

Table 1. Multiple regression analysis for soluble solid content

\begin{tabular}{lccc}
\hline \multicolumn{1}{c}{ Factor } & $\begin{array}{c}\text { Partial regression } \\
\text { coefficient }\end{array}$ & $\begin{array}{c}\text { Standard regression } \\
\text { coefficient }\end{array}$ & $\begin{array}{c}\text { Partial correlation } \\
\text { coefficient }\end{array}$ \\
\hline Constant & -44.500 & & \\
Specific gravity & 42.541 & 0.365 & 0.521 \\
Firmness & 2.020 & 0.817 & 0.747 \\
$\mathrm{~L}^{*}$ value & 0.033 & 0.125 & 0.092 \\
$\mathrm{a}^{*}$ value & 0.070 & 0.453 & 0.326 \\
\hline
\end{tabular}

Table 2. Multiple regression analysis for sugar content

\begin{tabular}{lccc}
\hline \multicolumn{1}{c}{ Factor } & $\begin{array}{c}\text { Partial regression } \\
\text { coefficient }\end{array}$ & $\begin{array}{c}\text { Standard regression } \\
\text { coefficient }\end{array}$ & $\begin{array}{c}\text { Partial correlation } \\
\text { coefficient }\end{array}$ \\
\hline Constant & -484.489 & & \\
Specific gravity & 486.689 & 0.446 & 0.606 \\
Firmness & 15.167 & 0.656 & 0.518 \\
$\mathrm{~L}^{*}$ value & -0.351 & -0.144 & -0.098 \\
$\mathrm{a}^{*}$ value & 0.531 & 0.363 & 0.244 \\
$\mathrm{~b}^{*}$ value & 0.487 & 0.116 & 0.141 \\
\hline
\end{tabular}

Table 3. Multiple regression analysis for organic acid content

\begin{tabular}{lccc}
\hline \multicolumn{1}{c}{ Factor } & $\begin{array}{c}\text { Partial regression } \\
\text { coefficient }\end{array}$ & $\begin{array}{c}\text { Standard regression } \\
\text { coefficient }\end{array}$ & $\begin{array}{c}\text { Partial correlation } \\
\text { coefficient }\end{array}$ \\
\hline Constant & -89.570 & & \\
Specific gravity & 94.280 & 0.572 & 0.753 \\
Firmness & 1.598 & 0.457 & 0.425 \\
L* value $^{*}$ alue & -0.076 & -0.215 & -0.178 \\
$\mathrm{~b}^{*}$ value & -0.085 & -0.384 & -0.255 \\
hue & 0.047 & 0.074 & 0.089 \\
\hline
\end{tabular}


was greatly affected by firmness and $\mathrm{a}^{*}$ value of tomato fruits. The standard regression coefficient of specific gravity and $L^{*}$ value were 0.365 and 0.125 , respectively. The effect of the factor on the soluble solid content was firmness, $a^{*}$ value, specific gravity and $L^{*}$ value in order from big to small. It was considered that although soluble solid content of tomato fruits was synthetically affected by many factors, it was greatly affected by firmness and $\mathrm{a}^{*}$ value. For sugar and organic acid contents (Tables 2 and 3), standard regression coefficient of firmness and specific gravity were the largest among the all factors. It was indicated that sugar and organic acid contents were markedly affected by firmness and specific gravity.

\section{CONCLUSIONS}

The synthetical analysis was carried out from specific gravity, firmness and hunter color index by using neural network to develop the nondestructive method for evaluating sugar, organic acid and soluble solid contents. The multiple regression analysis was also carried out. The results showed that there was no significant difference between experimental and calculated values of soluble solid content, indicating that soluble solid content could be predicted from specific gravity, firmness (calculated from $a^{*}$ value), $\mathrm{L}^{*}, \mathrm{a}^{*}$ and $b^{*}$ values by using neural network. It was also shown that the organic acid content could be estimated from specific gravity, firmness, hue, $L^{*}, a^{*}$ and $b^{*}$ values. But there was significant difference between experimental and calculated values of sugar, demonstrating that it was impossible to predict the sugar content from specific gravity, firmness, hue, $\mathrm{L}^{*}, \mathrm{a}^{*}$ and $\mathrm{b}^{*}$ values by neural network. For the multiple regression analysis, although soluble solid content of tomato fruits was synthetically affected by many factors, it was greatly affected by firmness and $a^{*}$ value of tomato fruits. For sugar and organic acid contents, both of them were markedly affected by firmness and specific gravity.

\section{REFERENCES}

Choi, K., G. Lee, Y. J. Han and J. M. Bun 1995 Tomato maturity evaluation using color image analysis. Trans. of the ASAE, 38: 171-176

Hobson, G. E., P. Adams and T. J. Dixon 1983 Assessing the color of tomato fruit during ripening. J. Sci. Food Agric., 34: 286-292

Hu, W., H., Yasutake, T., Uchino, E., Yasunaga, D., Hamanaka and Y., Hori 2002 Quality evaluation of tomato fruits by specific gravity and color, J. Fac. Agr., Kyushu Uni., 46: 381-389

Iwao, T., K. and Takeyama 1989 Studies of nondestructive quality evaluation of agricultural products-surface color and sugar component-. Bull. Fac. Agr. Shimane Univ., 21: 91-96

Judith, A. A. 1999 Quality measurement of fruits and vegetables. Postharvest Bio. Techno., 15: 207-225

Kawano, S., T. Fujiwara and M. Iwamoto 1933 Nondestructive determination of sugar content in Satsuma mandarin using near infrared transmittance. J. Japan. Soc. Hort. Sci., 62: 465-470

Kawano, S. 1998 Present condition of nondestructive quality evaluation techniques for fruits and vegetables. Food Preservation Sci., 24: 193-200

Olmo, M., A. Nadas and J. M. Garcia 2000 Nondestructive method to evalute maturity level of organs. J. Food Sci., 65: 365-369

Sugiura, T., H. Kuroda, D. Ito and H. Honjo 2001 Correlation between specific gravity and soluble solids concentration in grape berries, J. Japan. Soc. Hort. Sci., 70: 380-384

Yang, C. C. and M. S. Chinnan 1987 Modeling of color development of tomatoes in modified atmosphere storage. Trans. of the ASAE, 30: 548-553 